\title{
ROLE OF TRUCUT BIOPSY AS A DIAGNOSTIC TOOL IN PALPABLE BREAST LUMP
}

\author{
Rohan Chaphekar1, Suraj Jain², Rajesh Sharma33, Abhishek Kansal4, Prashansa Vijaywargiya ${ }^{5}$
}

${ }^{1}$ Senior Resident, Department of General Surgery, Shri Aurobindo Medical College and Postgraduate Institute, Indore ${ }^{2}$ Assistant Professor, Department of General Surgery, Shri Aurobindo Medical College and Postgraduate Institute, Indore. ${ }^{3}$ Professor, Department of General Surgery, Shri Aurobindo Medical College and Postgraduate Institute, Indore. ${ }^{4}$ Assistant Professor, Department of General Surgery, Shri Aurobindo Medical College and Postgraduate Institute, Indore. ${ }^{5}$ Senior Resident, Department of Conservative Dentstry and Endodontics, College of Dental Sciences and Hospital, Rau, Indore.

\section{ABSTRACT}

\section{BACKGROUND}

Breast lumps are an enormous source of anxiety to patients and a stratified approach has to be adopted to properly evaluate and treat them. An efficient and accurate evaluation can maximise cancer detection and minimise unnecessary testing and procedures. The present study is a sincere attempt to analyse different diagnostic modalities. For most diagnoses, all that is needed is an ounce of knowledge, an ounce of intelligence, and a pound of thoroughness."

\section{MATERIALS AND METHODS}

This descriptive observational study of the palpable breast lump was conducted on the female patients attending as outpatients and inpatients in the Department of Surgery for the period from 1st Jan 2013 to 30 th September 2014 at SAIMS Medical College and Postgraduate Institute, Indore. All the collected data were entered on a master chart. These were simple, descriptive, statistical methods. The demographic profile, clinical presentations, investigations like mammography and sonography and reports of trucut biopsies of the breast lumps were studied. At no stage of the study the individual identity of the patient was disclosed.

\section{RESULTS}

Total 57 patients were analysed in our study. The average age of women in this study was 42 years. Trucut biopsy correctly identified malignancy in 22 cases, Mammography in 21 cases, Clinical Examination in 18 cases and Combined Test in 22 cases. The combined test was $96.55 \%$ specific with malignant lesions.

\section{CONCLUSION}

The results of this study suggest that TCB is an accurate, reliable and a safe method of establishing the diagnosis of cancer in patients with breast lesions. Our results yielded a high sensitivity of $95.65 \%$ with $96.88 \%$ specificity when compared with FNAC in the diagnosis of breast cancer especially when radiology is not diagnostic. Thus, trucut biopsy should replace fine needle aspiration in the preoperative assessment of suspicious breast lumps.

\section{KEYWORDS}

Trucut biopsy, Breast lump, Mammography, Triple test.

HOW TO CITE THIS ARTICLE: Chaphekar R, Jain S, Sharma R. Role of trucut biopsy as a diagnostic tool in palpable breast lump. J. Evolution Med. Dent. Sci. 2017;6(62):4547-4551, DOI: 10.14260/Jemds/2017/984

\section{BACKGROUND}

Breast lumps are an enormous source of anxiety to patients and a stratified approach has to be adopted to properly evaluate and treat them. Though benign breast diseases are more common; there is a preoccupation with malignancy (Undue but understandable) amongst the patients and physicians alike. The ultimate diagnosis and treatment of a patient with a dominant breast mass, rests with the clinician. A dominant breast mass is defined as a solid or cystic lump that persists throughout the menstrual cycle. The preop assessment of a breast mass begins with a thorough history and systematic physical examination. However, it is generally accepted that this alone can be inadequate for an accurate

Financial or Other, Competing Interest: None.

Submission 27-06-2017, Peer Review 21-07-2017,

Acceptance 27-07-2017, Published 03-08-2017.

Corresponding Author:

Dr. Suraj Jain,

\#105 Veer Sahil Residency,

367 Vandana Nagar, Near Tilak Nagar,

Indore. Madhya Pradesh.

E-mail: drsurajain@yahoo.com

DOI: $10.14260 /$ jemds $/ 2017 / 984$

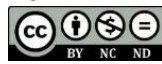

diagnosis. The breast is naturally multinodular and hence the difficulty in appreciating small nodules amidst the normal lumpiness is apparent. Apart from this is the varied expertise of the examiner in breast palpation. Thus, imaging of the breast using various physical imaging modalities is important.

Breast masses have a variety of aetiologies, benign and malignant. Most masses are benign. Fibroadenoma is the most common benign breast mass. Breast cancer is the most common cancer and the second leading cause of cancer deaths in women. Invasive ductal carcinoma is the most common malignancy. The incidence of the disease has shown a steep rise in women younger than 40 years of age. Not more than $50 \%$ of the women with breast cancer are alive and free of disease 10 years after the diagnosis.

An efficient and accurate evaluation can maximise cancer detection and minimise unnecessary testing and procedures. For effective management, multidisciplinary approach is essential.

Physical examination, mammography, ultrasonography, core needle biopsy, open excisional biopsy, thermography, fine needle aspiration cytology are all used to a greater or lesser extent in the diagnostic workup of a palpable breast 
mass. Various combinations of these approaches have been studied and have been found to increase the sensitivity and specificity over that of any one test alone. Many diagnostic tools are used in cases of suspected breast cancer as the famous triple assessment which was described in 1975(1) and it reduces dramatically the use of open biopsy.(1) (2) It was used principally for evaluating palpable breast lumps. Mammography is an essential component in the preoperative assessment of breast cancer. It serves to characterise and determine the extent of the mass and to evaluate the breasts for clinically occult lesions.(3) Triple test includes clinical assessment, mammography or ultrasonography and fine needle aspiration (FNA).(1)(3) The advent of core needle or Trucut biopsy (TCB) in the new millennium has resulted in many surgeons switching to TCB since it provides a sufficient amount of tissue for pathologists to make an accurate histological diagnosis. It is now the initial investigation method of choice for preoperative diagnosis of breast lesions. TCB can provide all the necessary details to guide both the surgeon and the oncologist in designing an appropriate therapeutic strategy for the management of patients with breast masses. ${ }^{(4)}$ The use of TCB also lessens the propensity of complicated surgical procedures and minimises patient stress. In patients with malignant lesions, in addition to having diagnostic significance, TCB also provides adequate tissue for the evaluation of molecular markers which have extreme therapeutic value.(4) Therefore, TCB is an accurate alternative to FNAC for the diagnosis of breast lesions. The advantage of trucut is that it has ability to obtain a core of tissue that is sufficiently large for HPE, providing more details of tumour structure, ability to distinguish between invasive and IDC. Any pathologist can interpret the results obviating the need for special skill of a cytopathologist. Large amount of prognostic information can be obtained including biological grade, receptor level and DNA analysis. There are some disadvantages of trucut biopsy like risk of seeding the needle tract with tumour cells; biopsy should be adjusted to avoid carrying potentially malignant tissue into the chest wall and false positive in case of radial scars.

\section{MATERIALS AND METHODS}

This was a descriptive observational study of the palpable breast lump conducted on the female patients attending as outpatients and inpatients in Department of Surgery from $1^{\text {st }}$ Jan 2013 to 30 ${ }^{\text {th }}$ September 2014 at Shri Aurobindo Medical College and P.G. Institute, Indore.

\section{Inclusion Criteria}

All female patients presenting with palpable breast lump with or without associated complaints in the outpatient department.

\section{Exclusion criteria}

1. Non-operative breast lumps.

2. Patients reluctant to undergo the study.

3. Patients who are already diagnosed cases of carcinoma breast.

The study protocol was reviewed by The Institutional

Ethical Committee of the institution and permitted by it.

Initial data collection was done at surgical outpatient and inpatient departments by attending doctors or investigators. Further data collection was done at Surgical Department during followup, and by Department of Radiology and Department of Pathology. Reports were recorded.

A detailed history and thorough physical examination of the patient having palpable breast lump was carried out and entered in the proforma. The patient was informed about the procedure and informed consent was obtained from the patient before subjecting to mammography and trucut biopsy of the breast lump. Each patient was put through this modified triple test. On the basis of a combined test, the lumps were grouped as malignant, benign or inconclusive.

The results of the combined test were then analysed individually and as a combination. Any component indicating a malignant report was taken as malignancy. Inconclusive reports were subject to excisional biopsy on an inpatient basis. Patients with malignancy were treated with definitive surgery. The post-procedural histopathological reports were compared to the results of the combined test to calculate Specificity and Sensitivity of each component of the combined test and the combined test as a whole in preoperative diagnosis of palpable breast lumps.

Tissue diagnosis by open biopsy was taken as gold standard and each individual test and combined test results were compared with the tissue biopsy.

Following variables were measured such as age of the patient, relevant history regarding duration of lump, pain, age of marriage, contraceptive use, first child birth age, smoking, family history and site of lump, clinical impression, findings of Mammography, reports of trucut needle biopsy and reports of Histopathology of open biopsy.

At the end of the study all the collected data was entered on a master chart and analysed by simple statistical method using averages. The results were depicted by charts and tables. At no stage of this study the identity of an individual patient was disclosed.

\section{RESULTS}

In our study, total 57 patients were included. All 57 patients underwent the Clinical Examination, Mammography and trucut Biopsy followed by excisional biopsy, the results of which were available for comparison. The average age of women in our study was 42 years. The youngest patient was 30 years and the oldest was 65 years. This confirms with the suitable age for subjecting patients to screening procedure followed worldwide i.e. above 40 years. 9 women were nulliparous of which only 3 had malignant lesions. The rest (48) were multiparous.

On excisional biopsy, the 57 lumps were confirmed histopathologically as either Malignant $(n=24)$ or Benign $(n=33)$. The pathological reports were as follows.

\begin{tabular}{|c|c|}
\hline Type of Malignant Tumours & Number of Cases \\
\hline Intra ductal carcinoma & 20 \\
\hline Lobular carcinoma & 01 \\
\hline Medullary carcinoma & 01 \\
\hline $\begin{array}{l}\text { Malignant cystosarcoma } \\
\text { phyllodes }\end{array}$ & 01 \\
\hline Carcinosarcoma & 01 \\
\hline Total Number of Cases & 24 \\
\hline \multicolumn{2}{|c|}{$\begin{array}{c}\text { Types of Malignant Tumours Confirmed } \\
\text { Histopathologically }\end{array}$} \\
\hline
\end{tabular}




\begin{tabular}{|c|c|}
\hline Type of Benign Tumours & Number of Cases \\
\hline Fibroadenoma & 14 \\
\hline Fibrocystic disease & 10 \\
\hline Breast abscess & 06 \\
\hline $\begin{array}{l}\text { Benign cystosarcoma } \\
\text { phyllodes }\end{array}$ & 03 \\
\hline Total number of cases & 33 \\
\hline
\end{tabular}

\begin{tabular}{|c|c|c|}
\hline Consistency & HPR-Malignant & HPR-Benign \\
\hline Soft & 0 & 1 \\
\hline Firm & 5 & 29 \\
\hline Hard & 19 & 3 \\
\hline \multicolumn{2}{|c|}{$\begin{array}{c}\text { Comparative Study of Consistency of } \\
\text { lump with Histopathology Report }\end{array}$} \\
\hline
\end{tabular}

Clinical examination finding of a hard, irregular lump was more likely to be malignant, while a soft or firm mass with regular surface suggested benign lesions. Benign lesions most often confused with malignancy were benign cyst sarcoma phyllodes \& fibrocystic disease.

\begin{tabular}{|c|c|c|}
\hline $\begin{array}{c}\text { Clinical } \\
\text { Examination }\end{array}$ & HPR-Malignant & HPR-Benign \\
\hline Malignant & 18 & 1 \\
\hline Benign & 2 & 23 \\
\hline Inconclusive & 4 & 9 \\
\hline \multicolumn{2}{|c|}{ Comparative Study of Clinical } \\
Examination with Histopathology \\
\hline
\end{tabular}

Amongst 19 cases which were diagnosed as malignant on C/E, 18 (94.74\%) were malignant as well on histopathology, but 1 was benign. Also, amongst 25 cases that were diagnosed as benign on C/E, $23(92 \%)$ were benign too on histopathology and 2 were malignant. Thus, Sensitivity and Specificity of Clinical Examination in diagnosing malignancy was $90 \%$ and $95.83 \%$ respectively.

\begin{tabular}{|c|c|c|}
\hline Mammography & HPR-Malignant & HPR-Benign \\
\hline Malignant & 21 & 4 \\
\hline Benign & 2 & 28 \\
\hline Inconclusive & 1 & 1 \\
\hline \multicolumn{2}{|c|}{$\begin{array}{c}\text { Comparative Study of Mammography } \\
\text { with Histopathology Report }\end{array}$} \\
\hline
\end{tabular}

Amongst 25 cases which were diagnosed as malignant on MG, 21 (84\%) were malignant as well on histopathology, but 4 were benign. Also, amongst 30 cases that were diagnosed as benign on MG, 28 (93.33\%) were benign too on histopathology and 2 were malignant. Thus, Sensitivity and Specificity of Mammography in diagnosing malignancy was $91.30 \%$ and $87.5 \%$ respectively.

\begin{tabular}{|c|c|c|}
\hline Trucut Biopsy & HPR-Malignant & HPR-Benign \\
\hline Malignant & 22 & 1 \\
\hline Benign & 1 & 31 \\
\hline Inconclusive & 1 & 1 \\
\hline \multicolumn{2}{|c|}{ Comparative Study of Trucut } \\
Biopsy Report with Histopathology \\
\hline
\end{tabular}

Amongst 23 cases which were diagnosed as malignant on TCB, 22 (95.65\%) were malignant as well on histopathology, but 1 was benign. Also, amongst 32 cases that were diagnosed as benign on TCB, $31(96.88 \%)$ were benign too on histopathology and 1 was malignant. Thus, Sensitivity and Specificity of Trucut Biopsy in diagnosing malignancy was $95.65 \%$ and $96.88 \%$ respectively.

\begin{tabular}{|c|c|c|}
\hline $\begin{array}{c}\text { Combined Test } \\
\text { Result }\end{array}$ & HPR-Malignant & HPR-Benign \\
\hline Malignant & 22 & 1 \\
\hline Benign & 0 & 28 \\
\hline Inconclusive & 2 & 4 \\
\hline \multicolumn{3}{|c|}{$\begin{array}{l}\text { Comparative Study of Combined } \\
\text { Test Result with Histopathology }\end{array}$} \\
\hline
\end{tabular}

Amongst 23 cases which were diagnosed as malignant on CTR, 22 (95.65\%) were malignant too on histopathology, but 1 was benign. Also, amongst 28 cases that were diagnosed as benign on CTR, 28 (100\%) were benign too on histopathology and none was malignant. Thus, Sensitivity and Specificity of Combined Test in diagnosing malignancy was $100 \%$ and $96.55 \%$ respectively.

\begin{tabular}{|l|c|c|c|c|}
\hline & $\begin{array}{c}\text { Clinical } \\
\text { Examination }\end{array}$ & $\begin{array}{c}\text { Mammo- } \\
\text { graphy }\end{array}$ & $\begin{array}{c}\text { Trucut } \\
\text { Biopsy } \\
\text { Report }\end{array}$ & $\begin{array}{c}\text { Combined } \\
\text { Test Result }\end{array}$ \\
\hline Sensitivity & $90 \%$ & $91.30 \%$ & $95.65 \%$ & $100 \%$ \\
\hline Specificity & $95.83 \%$ & $87.50 \%$ & $96.88 \%$ & $96.55 \%$ \\
\hline \multicolumn{4}{|c|}{ Statistical Analysis of the Study } \\
\hline
\end{tabular}

Amongst the individual tests, Clinical Examination was more likely to miss a malignancy (Sensitivity 90\%) as against Mammography (Sensitivity 91.30\%) or Trucut Biopsy (Sensitivity 95.65\%).

Trucut biopsy correctly identified malignancy in 22 cases, Mammography in 21 cases, Clinical Examination in 18 cases and Combined Test in 22 cases.

The combined test was $96.55 \%$ specific with malignant lesions. But 1 case was misdiagnosed as malignancy and turned out to be benign cystosarcoma phyllodes, a benign lesion. Thus, combined test, though had false positives with respect to malignancy had no false negatives. These data are comparable to the original triple test with its sensitivity (65\%-96\%) and specificity (55\%-98\%) as reported in various studies.

\section{DISCUSSION}

Clinical evaluation has been reported to be an essential first step in the preoperative diagnosis of breast cancer. Clinical examination finding of a hard, irregular lump was more likely to be malignant, while a soft or firm mass with regular surface suggested benign lesions. Benign lesions most often confused with malignancy were benign cystosarcoma phyllodes \& fibrocystic disease. Hermansen $\mathrm{C}$ et al in 1984(5) prospectively studied 650 breast tumours and applied the term "Triple test" to the triad of physical examination, mammography and FNAC used to diagnose them. Cusick JD et al in 1990(6) reported about using the Trucut (Travenol Lab) needle biopsy (TCNB) as the primary method of diagnosing carcinoma of the breast in patients with suggestive masses. Physical examination, mammography, and fine needle aspiration were each assigned a score of 1,2 , or 3 for benign, suspicious, or 
malignant results. The TTS has a minimum score of 3 (Concordant benign) and a maximum score of 9 (Concordant malignant). The TTS was correlated with subsequent histopathologic analysis or follow-up. Lesions with a TTS greater than or equal to 5 were excised for histologic confirmation, whereas lesions with scores less than or equal to 4 were either excised or followed clinically. The TTS reliably guided evaluation and treatment of palpable breast masses. Masses scoring 3 or 4 were always benign. Masses with scores greater than or equal to 6 were malignant and were treated accordingly.(1)

Amongst 19 cases which were diagnosed as malignant on C/E, 18 (94.74\%) were found malignant on histopathology but 1 was benign in histopathological examination. Also amongst 25 cases that were diagnosed as benign on C/E, 23 $(92 \%)$ were found to be benign on histopathology and 2 were found malignant. Thus, Sensitivity and Specificity of clinical examination in diagnosing malignancy was $90 \%$ and $95.83 \%$ respectively. It is comparable to the results obtained in similar studies cited below correlating clinical examination with histopathology of breast lumps.(5)(7)(8)(9)

The advent of core needle or Trucut biopsy (TCB) in the new millennium has resulted in many surgeons switching to TCB since it provides a sufficient amount of tissue for pathologists to make an accurate histological diagnosis. Amongst 23 cases which were diagnosed as malignant on TCB, 22 (95.65\%) were malignant on histopathology, but 1 was benign. Also, amongst 32 cases that were diagnosed as benign on TCB, 31 (96.88\%) were benign too on histopathology and 1 was malignant. Thus, Sensitivity and Specificity of Clinical Examination in diagnosing malignancy was $95.65 \%$ and $96.88 \%$ respectively. It is comparable to the results obtained in similar studies cited below correlating trucut biopsy with histopathology of breast lumps.(6) (8) (10).

Mammography is an essential component in the preoperative assessment of breast cancer. It serves to characterise and determine the extent of the mass and to evaluate the breasts for clinically occult lesions. Amongst 25 cases which were diagnosed as malignant on MG, 21 (84\%) were malignant as well on histopathology, but 4 were benign. Also, amongst 30 cases that were diagnosed as benign on $\mathrm{MG}$, $28(93.33 \%)$ were benign too on histopathology and 2 were malignant. Thus, Sensitivity and Specificity of Clinical Examination in diagnosing malignancy was $91.30 \%$ and $87.5 \%$ respectively. It is comparable to the results obtained in similar studies cited below correlating mammography with histopathology of breast lumps.(5)(7)(8)

Amongst 23 cases which were diagnosed as malignant on CTR, 22 (95.65\%) were malignant too on histopathology, but 1 was benign. Also, amongst 28 cases that were diagnosed as benign on CTR, 28 (100\%) were benign too on histopathology and none was malignant. Thus, Sensitivity and Specificity of Combined Test in diagnosing malignancy was $100 \%$ and $96.55 \%$ respectively. It is comparable to the results obtained in similar studies cited below correlating Combined Test with histopathology of breast lumps.(8)(11)

\section{CONCLUSION}

Fine needle aspiration cytology (FNAC) was the principal mode of diagnosis in most specialist centres, but as FNAC has failed to provide a reliable preoperative diagnosis of breast cancer, trucut biopsy has taken over now. Various reasons have been attributed for a low sensitivity for FNAC including proficiency of the aspirator, experience of the pathologist, size of the lesion and histological type of the tumours. These patients then need a core biopsy or open biopsy, thus delaying their preoperative diagnosis. The results of this prospective study suggest that TCB is an accurate, reliable and a safe method of establishing the diagnosis of breast cancer in patients with breast lesions. Patients in the current study who had benign breast lesions diagnosed accurately by TCB were saved a lot of expenses and did not undergo unnecessary surgical procedures that would have been an additional burden on the healthcare system. The use of TCB also lessens the propensity of complicated surgical procedures and minimises patient stress. In patients with malignant lesions, in addition to having diagnostic significance, TCB also provides adequate tissue for the evaluation of molecular markers which have extreme therapeutic value. Therefore, it is proposed that TCB is an accurate alternative to FNAC for the preoperative diagnosis of breast lesions and so should replace FNAC in the original Triple Assessment test for accurate preoperative breast lump diagnosis.

\section{REFERENCES}

[1] Morris KT, Pommier RF, Morris A, et al. Usefulness of the triple test score for palpable breast masses. Arch Surg 2001;136(9):1008-13.

[2] Green B, Dowley A, Turnbull LS, et al. Impact of fineneedle aspiration cytology, ultrasonography and mammography on open biopsy rate in patients with benign breast disease. Br J Surg 1995;82(11):1509-11.

[3] Eltahir A, Jibril JA, Squair J, et al. The accuracy of onestop diagnosis for 1,110 patients presenting to a symptomatic breast clinic. J R Coll Surg Edinb 1999;44(4):226-30.

[4] Rikabi A, Hussain S. Diagnostic usefulness of Trucut biopsy in the diagnosis of breast lesions. Oman Med J 2013;28(2):125-7.

[5] Hermansen C, Poulsen HS, Jensen J, et al. Palpable breast tumors: "triple diagnosis" and operative strategy: results of a prospective study. Acta Chir Scand 1984;150(8):625-8.

[6] Cusick JD, Dotan J, Jaecks RD, et al. The role of Trucut needle biopsy in the diagnosis of carcinoma of the breast. Surg Gynecol Obstet 1990;170(5):407-10.

[7] Sumboonnanonda K, Chiemchanya S. Triple diagnosis in carcinoma of the breast: a replacement for open biopsy. J Med Assoc Thai 1998;81(4):292-6.

[8] Clarke D, Sudhakaran N, Gateley CA. Replace fine needle aspiration cytology with automated core biopsy in the triple assessment of breast cancer. Ann R Coll Surg Engl 2001;83(2):110-2.

[9] Mande N, Gakwaya AM, Byanyima RK, et al. The triple assessment in the preoperative evaluation of patients with breast cancer in Mulago hospital, KampalaUganda. East and Central African Journal of Surgery 2004;9(2):111-6. 
[10] Homesh NA, Issa MA, El-Sofiani HA. The diagnostic accuracy of fine needle aspiration cytology versus core needle biopsy for palpable breast lump(s). Saudi Med J 2005;26(1):42-6.
[11] Shiralkar S, Champ C, Lewis M, et al. Replace fine needle aspiration cytology with automated core biopsy in the triple assessment of breast cancer. Ann R Coll Surg Engl 2002;84(2):146-7. 